\title{
"To follow or not to follow?" How Belgian health journalists use Twitter to monitor potential sources
}

\author{
Sarah Van Leuven and Annelore Deprez
}

Journal of Applied Journalism and Media Studies (in press)

\begin{abstract}
$\underline{\text { Abstract }}$
Digital technology, the internet and mobile media are transforming the journalism and media landscape by influencing the news gathering and sourcing process. The empowering capacities of social media applications may constitute a key element for more balanced news access and "inclusive journalism". We will build on two contrasting views that dominate the social media sourcing debate. On the one hand, literature shows that journalists of legacy media make use of social media sources to diversify their sourcing network including bottom-up sources such as ordinary citizens. On the other hand, various authors conclude that journalists stick with their old sourcing routines and continue to privilege top-down elite sources such as experts and government officials. In order to contribute to this academic debate we want to clarify the Twitter practices of professional Belgian health journalists in terms of how they use the platform to monitor potential sources. Therefore, we examined the 1146 Twitter "followings" of six Belgian health journalists by means of digital methods and social network analysis. Results show that top-down actors are overrepresented in the "following" networks and that Twitter's "following" function is not used to reach out to bottom-up actors. In the overall network, we found that the health journalists mainly use Twitter as a "press club" (Rupar, 2015) to monitor media actors. If we zoom in specifically on the "following" network of the healthrelated actors, we found that media actors are still important, but experts become the most followed group. Our findings also underwrite the "power law" or "long tail" distribution of social network sites as very few actors take a central position in the "following" lists while the large majority of actors are not systematically monitored by the journalists.
\end{abstract}

\section{Introduction}

The widest possible representation of viewpoints in the news is an essential characteristic of the "inclusive society" and a precondition for democratic public deliberation (Habermas, 1974, 1992; Rupar, 2015). Unfortunately, this idea of "inclusive journalism" or "multiperspectival news" (Gans, 2011) has remained a never-realized ideal in the "mass society" where news access is strongly determined by the distribution of power and resources. Studies repeatedly demonstrated how top-down or elite actors -such as politicians, government institutions, experts and well-resourced companies- enjoy privileged news access compared to bottom-up or nonelite actors, including ordinary citizens and civil society organizations (Cottle, 2000; Gans, 
1979, 2011; Hall et al., [1978] 1999; Sigal, [1973] 1999; Wolfsfeld, 2011). These news gathering routines have become established over decades and are ways for journalists to deal with time and resource limitations while ensuring credibility, objectivity and productivity (Gans, 1979; Shoemaker \& Reese, 1996; Sigal, [1973] 1999). Some elite sources are considered particularly reliable because of their institutional power (e.g. government officials), representative status (e.g. elected politicians) or knowledge of a certain topic (experts) (Hall et al., [1978] 1999). This "hierarchy of credibility" combined with a working context of time constraints and efficiency considerations results in a situation where "highly credible" sources are consulted more often than "less credible" non-elite sources such as ordinary citizens or volunteer organizations whose information requires more verification and cross-checking. Other sources such as large companies and lobby groups are less credible but equally successful in gaining news access because they possess the necessary financial and social resources to provide "information subsidies" or page-ready content to journalists (Cottle, 2000; Davis, 2000; Gandy, 1982; Gans, 1979, 2011; Lewis et al., 2008). In a context of cost-cutting and increasing workloads for journalists who are tied to their desks, these "information subsidies" are a welcome resource to keep up with the $24 / 7$ news cycle.

Nonetheless, this approach to journalist-source relations is increasingly criticized in light of the advancements in digital technologies. The empowering capacities of social media applications may constitute a key element for more balanced news access and "inclusive journalism". The increased speed of information dissemination, the interactivity and the connectivity that characterize social media sites offer the potential for journalists to revise their sourcing practices in light of the often-cited dangers of heavy reliance on elite sources (Castells, 2008, 2011; Gans, 1979, 2011; Heinrich, 2011). Especially Twitter has proven to be the preferred social media news gathering channel for professional journalists due to its characteristics that invite information sharing (Russell et al., 2015). Yet the question remains whether and how journalists make use of the new possibilities available through social media. We build on two contrasting views that dominate the social media sourcing debate in the "network society" (Castells, 2008; Heinrich, 2011). On the one hand, there is the bottom-up perspective suggesting that social media channels allow users to spread information cheaply and instantaneously throughout their network. As a result, they can open the news gates for non-elite or bottom-up sources (Kaplan \& Haenlein, 2010). On the other hand, several authors conclude that journalists stick with their old top-down sourcing routines and continue to privilege elite sources, also through social media channels (Author, 2013). Some studies point out that social media channels are "colonized" by elite sources, who understand the potential of social media to strengthen relations with journalists (Broersma \& Graham, 2012).

With this paper we want to contribute to this academic debate and clarify the social media sourcing practices of professional journalists. More specifically, we focus on health journalists because studies suggest that journalists covering specialty areas are more likely to explore new tools and experiment with new practices, including social media sourcing (Molyneux \& Holton, 2015). By means of digital methods and social network analysis, we examined the 1146 Twitter "followings" of six Belgian print journalists specialized in health news and having an active Twitter account. In what follows, we will first elaborate on the potential of social media channels and specifically Twitter for news sourcing. We then build on two different 
perspectives on news sourcing in the "network society" before turning to our empirical study of Belgian health journalists" "following" practices on Twitter.

\section{The potential of Twitter for news sourcing}

In recent years, sourcing practices have been reconsidered in light of the arrival of advanced digital technologies in a still evolving context of globalization and commercialization (Author, 2013). Our focus is set on Web 2.0 social media platforms, that are characterized by non-linear, decentralized and multi-directional information flows between the (almost) uncountable nodes in the network (Heinrich, 2012; Kaplan \& Haenlein, 2010). Several authors contend that Twitter has the highest potential for news sourcing due to its characteristics that invite information sharing such as the @mentions and retweets (Carrera Alvarez et al., 2012; Neuberger et al., 2014; Russell et al., 2015). Today, many journalists and news organizations use Twitter for professional purposes. For example, in the UK, 96 per cent of the journalists use the platform on a daily basis (Canter, 2015). The question is to what extent they use it for news sourcing. Several studies have examined the four different uses of Twitter by news organizations and professional journalists: to seek information, but also to dialogue with the audience, to publish, and to profile themselves or their organizations (Author, 2013; Neuberger et al., 2014; Noguera Vivo, 2013). Most studies worldwide find that "journalists use Twitter to distribute and viralize pre-existing content much more than to create new content using social media crowdsourcing and newsgathering opportunities" (Carrera Alvarez et al., 2012, p.51). Despite the huge potential that Twitter provides for traditional media, they "use a 2.0 tool with a clear 1.0 mentality" (Herrera \& Requejo, 2012, p.80), mainly to spread information or for selfpromotional purposes and branding (Hanusch \& Bruns, 2016; Greer \& Ferguson, 2011; Molyneux \& Holton, 2015; Neuberger et al., 2014; Noguera Vivo, 2013; Pew Research Center, 2011; Russell et al., 2015). Journalists are often addressed by followers on Twitter, but most studies find that the interactive potential of the platform is largely neglected (Engesser \& Humprecht, 2015; Hedman, 2016; Neuberger et al., 2014).

When it comes to sourcing and news gathering, journalists can "follow" Twitter users who can provide information that might contribute to the coverage of a certain topic (Hill, 2010). Twitter can provide story ideas and can inform journalists on topics the audience is interested in (e.g., via trending Twitter hashtags; Farhi, 2009; Hermida, 2010; Hill, 2010). Studies find that journalists are very optimistic and enthusiastic about the added value of social media sourcing. For example, $65 \%$ of Dutch-speaking journalists in Belgium believe that social media can be an important information channel in the news gathering process (Author, 2015). Carrera Alvarez et al. (2012) interviewed 50 Spanish journalists and found that most of them agree that social networks affect reporting in the sense that it can lead to a broadening of sources $(80 \%)$ and that it can be a source for story ideas (72\%). However, when it comes to the actual use of social media as information channels, the findings are mixed.

On the one hand, for example, Carrera Alvarez et al. (2012) found that very few journalists use Twitter to contact citizen sources (52\%), to get information from institutional agendas (42\%) and for investigative reporting (24\%). Lawrence et al. (2014) analyzed tweets from US journalists over the course of the 2012 US presidential campaign and found that only $1.7 \%$ of the tweets contained any kind of request for story ideas or information. In Belgium, only $33 \%$ 
of all Dutch-speaking journalists say that they consult Twitter on a daily basis specifically as an information source (Author, 2015). Author (2014) conducted a content analysis of Belgian newspapers and found references to social media sources in only $1.5 \%$ of all articles. Other studies also suggested that in the everyday news production process, social media are rarely used as information channels (Noguera Vivo, 2013; Pew Research Center, 2011). Many journalists admit they struggle with information overload, language hurdles, and the doubted reliability and verification issues of online information (Carrera Alvarez et al., 2012; Hermida, 2010; Lariscy et al., 2009). Neuberger et al. (2014, p.351) conclude that "Twitter is hardly ever used for gathering facts and background information or cross-checking information, but is used instead for "soft" research goals" such as an assessment of the public mood regarding current issues or the observation of Twitter as a phenomenon.

On the other hand, Paulussen and Harder (2014) found evidence that social media sourcing is gradually gaining more prominence in the newsroom. Journalists may also be more inclined to consult social media as an information channel in the context of breaking news or media restrictions where they cannot (immediately) access the area themselves and therefore try to learn from on-the-ground sources (Author, 2015; Lotan et al. 2011). Moreover, studies suggest that journalists covering specialty areas are more likely to explore new tools and experiment with new practices including social media sourcing such as political journalists (Broersma \& Graham, 2012), regional or local journalists (Canter, 2015) or health journalists (Holton, 2013; Molyneux \& Holton, 2015). Therefore we focus on the social media sourcing practices of Belgian health journalists. But first, we will build on two contrasting perspectives that dominate the debate on how journalists use social media as a channel to get in touch with potential sources.

\section{News sourcing reconsidered in the network society?}

The bottom-up perspective contends that the empowering capacities of social media may constitute a key element for more balanced news access. In accordance with the work of Castells (2008, 2011), some scholars state that the network is the "new dominant social structure in contemporary societies [...] in which our ability to connect beyond time and space constraints takes center stage" (Heinrich, 2011, p.23-24). In the context of news production, Heinrich (2011) contends that journalistic organizations should go through a structural transformation and adapt to the sphere of "network journalism" in order to allow journalists to navigate the new global information map. "A large array of potential new sources can now be reached via many connection points other than (traditional) official sources such as governmental institutions or press offices. Instead of a rather 'closed' system of newsgathering, production and distribution, in which only a limited number of partakers had the power to make and shape news, the network journalism sphere is an open space of information exchange" (Heinrich, 2012, p.767). Today more than ever before, bottom-up sources -as nodes in the network- have at their disposal the means to gain access to journalists. The sourcing opportunities within the global, network journalism sphere do correspond with the claim for "inclusive journalism" or "multiperspectival news" made by Gans (2011). He demands that news coverage should represent the general public and make their views and voices heard to foster public discourse. Allowing a greater diversity of sources including ordinary citizens into the news production process might help to establish greater diversity in viewpoints and thus assist to balance agenda 
setting interests of different groups. Elite sources are but one of many information nodes on Twitter and other social media. Citizens and other civil society actors have evolved from a rather passive audience into a more active and engaged group. In contrast with the traditional means for information dissemination such as press releases, Twitter allows users to spread information cheaply and instantaneously throughout their network. As a result, it can open the news gates for bottom-up sources who can add important pieces of information to news stories (Author, 2015; Castells, 2008; Kaplan \& Haenlein, 2010). These sources were often neglected in traditional news coverage, due to time and other constraints, but they are easily accessible today through social media platforms and especially Twitter.

Paulussen and Harder (2014) found confirmation for the bottom-up perspective in that $44 \%$ of the social media sources in their content analysis of Belgian newspapers originated from ordinary citizens. However their tweets are usually paraphrased as "mostly social media references to unknown people are made in collective and anonymous terms, as a way to represent the voice of the public" (Paulussen \& Harder, 2014, p.548). In contrast, tweets originating from elite sources are less often used by journalists, but if they are, they are quoted verbatim, which adds to their agenda building power (see below). In the context of the Arab Spring, Author (2015) found that in Belgian newspapers, social media were consulted in 10\% of the articles about Egypt, Tunisia and Syria, mainly to contact local ordinary citizens. However, examples where social media sourcing added value to the coverage were exceptional. In most cases, the newspapers displayed Twitter and Facebook quotes in a separate column to illustrate the content of news articles without taking responsibility for the content of the tweets and posts. Most of the quotes expressed the experiences and emotions of participants in the uprisings (e.g., "You can do it!!! Tunisia supports u! Good luck (-)") as a way of capturing the public mood. Viewed from the perspective of "network" or "inclusive" journalism, one could interpret this shift in sourcing practices as a move to allow more bottom-up sources in the coverage. Conversely, one can still question how far these personal comments add depth and new viewpoints to the coverage, especially when they are not integrated in the news article but instead "packaged away from traditional media coverage" (Heinrich, 2012, p.769).

The top-down perspective states that social media sourcing practices reinforce the privileged news access of elite sources. Traditional media brands increasingly cut costs for purely economic reasons, resulting in "churnalism", or the production of stories in "greater numbers at greater speed and of much worse quality" (Davies, 2008, p.62). Journalists' workload has increased even more reflecting the increasing number of pages, supplements and online editions (Lewis et al., 2008). Given the current media ecology, information subsidies generated by elite sources are said to circulate barrier-free and uncontested within the media and the public sphere in a top-down process (Davies, 2008). Moreover, several studies point out that social media channels are also "colonized" by elite sources, who understand the potential of social media to strengthen relations with journalists. Broersma and Graham (2012), in their content analysis of Dutch and British tweets that were used as sources in election coverage, found that most tweets originated from elite sources. This was especially the case in the Netherlands, where the newspapers sourced almost exclusively politicians' tweets. The fact that the tweets were usually verbatim incorporated in the news instead of paraphrased furthermore suggests that Twitter boosts the agenda building power of elite sources, whose messages are distributed unfiltered to 
a mass audience, as also Parmelee (2014) found in the United States. The same tendency was found for the British papers, though less outspoken as there was also room for vox pop tweets, especially in the popular papers. "However, it would be misleading to suggest that twittering citizens are gaining more control over news coverage, as most tweets cited from the vox pop were humorous and entertaining in nature" (Broersma \& Graham, 2012, p.417). D'heer and Verdegem (2014) took a different approach and investigated conversation patterns on Twitter between political actors, media actors and citizens during the 2012 Belgian elections. They found that citizens are well represented in the network, but they do not very often interact with politicians and media actors. In contrast, politicians and media actors are strongly connected in a reciprocal manner which suggests that political journalists mainly use Twitter to extend their offline relations with politicians and not to establish more diversified networking practices including ordinary citizens talking about politics. In a similar setup, Rupar (2015) studied 49 New-Zealand journalists' use of Twitter in the 2014 General Election and recorded that $70 \%$ of @ mentions were directed at other journalists, labelling Twitter as a "press club" where journalists interact with other journalists and media-related twitter accounts. Lawrence et al. (2014) made similar conclusions in their study of US journalists' tweets during the 2012 presidential campaign. Russell et al. (2015, p.925) also confirm this finding in their analysis of journalists' tweets posted during the two weeks US government shutdown in October 2013: "journalistswere more likely to interact through retweets and @ mentions with other journalists than with public officials or other citizens". Taken together, these findings indicate that journalists mainly use Twitter to extend their offline top-down sourcing practices and connect with elite sources and their own peers, namely other journalists and media outlets.

\section{Sourcing practices in health news: an old or new story?}

With this paper we want to clarify this debate about the bottom-up or top-down sourcing practices of journalists using Twitter as an information channel and more specifically we will zoom in on health journalists because studies indicate that specialized reporters more often experiment with new tools (Molyneux \& Holton, 2015). In addition, health news is a crucial source of information for citizens to manage their own health and to participate in the public debate about health issues (Hinnant et al., 2012). Yet research has confirmed the tendency of elite dominance when it comes to health news sources. Especially experts such as health scientists but also health professionals such as medical doctors are shown to be the chosen sources. Journalists also routinely search medical and scientific journals for story ideas and information (Len-Rios et al., 2009; Rowe et al., 2003; Van Trigt et al., 1994). Several authors find an explanation for this finding in the often complex and technical matter of health news. Combined with the fact that specialized journalists are increasingly replaced with generalists who have no or limited expertise in the matter, it is not a very big surprise that journalists often turn to experts on the matter for clarification and contextualization (Berkowitz, 1990; Gans, 1979; Holton, 2013; Rowe et al., 2003). "Journalists use expert sources in health stories to provide perspective, contribute balance to the story, discuss research implications, and legitimize other research" (Len-Rios et al., 2009, p.318). Moreover, some authors focus on the mediatization of science, as scientists and scientific organizations have successfully intensified their media efforts in response to the increasing pressure to legitimize research and maximize the acquisition of research funds (Sumner et al., 2014; Williams \& Gajevic, 2013). Other 
important sources are politicians and government officials who are involved in health policy (Rowe et al., 2003) and, like in all news coverage and as symptom of the competitive media environment, other media are routinely monitored for story ideas (Len-Rios et al., 2009). Despite the availability of easy-to-use information subsidies, studies point out that health journalists are not keen to use corporate information subsidies, and if they do, they confront the corporate information with other sources (Len-Rios et al., 2009; Van Trigt et al., 1994).

Ordinary citizens are rarely represented in health news "apart from occasional reference to add a personal dimension or to provide human interest" (Rowe et al., 2003, p.682). Nonetheless, although they are not thought to powerfully shape media agendas, Len-Rios et al. (2009) found that citizens are important sources for health journalists for story ideas. Considering the complexity of health issues, some authors wonder whether the call for "inclusive journalism" is actually justified for this specific news topic. For example, in a recurring critique on sourcing ordinary citizens in the news, Habermas $(1974,1992)$ states that this approach does not add depth and new viewpoints to the message but rather dumbs-down the information in the news article. In contrast, Gans (2011) demands that journalists and news media should represent the general public and make their views and voices heard to foster public discourse. Other authors stress that this journalistic approach allows more ordinary people to understand the news from real-life experiences (McNair, 2009). For example, in an article covering technical debates about the reimbursement of drugs designed to treat orphan diseases, even when testimonies of people suffering from a certain orphan disease do not add a rational and well-considered argument to the public debate about the reimbursement, they can still add a new layer to the discussion in telling the story from real-life experiences.

\section{Research questions and methodology}

The above literature review demonstrates that little research focuses on sourcing practices in health journalism within the digital media ecology. The analysis presented in this article investigates the Twitter profiles of six Belgian health journalists to search for signs of top-down or bottom-up sourcing practices. On the one hand, Twitter can be used by health journalists to allow a greater diversity of sources into the news production process which might help to establish greater diversity in viewpoints and thus assist in balancing agenda-setting interests of different groups. On the other hand, it is possible that health journalists have extended their offline sourcing practices to Twitter and use the platform mainly to get in touch with elite sources, especially experts, government/politicians and other media. With this paper we want to contribute to this academic debate and clarify the Twitter practices of professional Belgian health journalists in terms of how they use the platform to monitor ("follow") potential sources. From this point of departure, we define the following research question:

RQ 1: Which actors (elite/top-down versus non-elite/bottom-up) are most followed by Belgian health journalists?

We focus on the Dutch-speaking part of the country (Flanders), because most health issues in Belgium are organized on the regional level, resulting in largely different networks of healthrelated actors and sources in the different parts of the country. A search in the database of the Flemish Journalists Association showed that only 14 journalists are specialized in health news, 
which confirms the international tendency that increasingly generalists instead of specialized journalists cover health issues (Len-Rios et al., 2009). In addition, it showed that mainly print media invest resources in specialized health journalists. We can identify several explanations for this finding, e.g. that they have more room for in-depth news coverage compared to more volatile audiovisual media, or the existence of niche magazines that focus on science and even health. In a next step, we checked whether these health journalists have an active Twitter account. This resulted in a final sample of all six Belgian print journalists specialized in health news. Dieter De Cleene is employed by the scientific weekly magazine EOS. Leen Baekelandt works for Plus Magazine, a monthly magazine aiming at men and women aged 50 years and older. Marleen Finoulst graduated as a physician but she is currently the editor-in-chief of the monthly health magazine Bodytalk. Veerle Maes is journalist for the monthly lifestyle magazine Goed Gevoel that focuses mainly on women. Maxie Eckert and Sara Vandekerckhove work respectively for the quality daily newspapers De Standaard and De Morgen.

We examined the Twitter practices of Belgian health journalists by means of social network analysis and digital methods. First, we used the Twitter REST API and the R package twitteR to collect all "followings" of each journalist. These "followings" can be considered as potential sources since studies indicate that journalists generally follow and thus monitor actors because they expect them to share newsworthy information (Hill, 2010). This resulted in an automatically generated list of 1454 "followings" of our 6 journalists, or 1146 unique Twitter profiles (some actors are followed by more than one journalist) collected on 4 July 2015. Based on their name and description, each "following" or potential source was then manually coded in terms of eight different categories or "identity attributes". We identified on the one hand six types of elite or top-down actors: media, (pharmaceutical) industry, political actors, government institutions, health insurance companies and (academic) medical experts. On the other hand we identified two types of non-elite or bottom-up actors: citizens (patient organizations, consumer organizations, ordinary citizens) and civil society organizations (NGOs, volunteer organizations, foundations, non-profit organizations).

We also make a distinction between health-related (e.g. the Minister of Health, a physician) and non-health-related (e.g. the Minister of Finances, a celebrity) actors that journalists can follow. Since the studied networks are those of health journalists and they will probably mainly use health-related sources in their news reporting, we specifically studied the subsample of healthrelated actors $(\mathrm{N}=303)$ in more detail. We put forward the second research question:

RQ2: Which health-related actors (elite/top-down versus non-elite/bottom-up) are most followed by Belgian health journalists?

Statistical analysis was carried out using SPSS 22 and all reported results are significant at $\mathrm{p}$ $\leq 0.05$ level. In a next step, we used Gephi, a visualization tool, to construct the networks of the studied health journalists by mapping the connections between health journalists and the monitored actors. We first reconstructed the ego-network of each health journalist and then aggregated the six networks to get insight into the overall "following" network (figure 1). Actors who are followed by several journalists take a more central position in the overarching "following" network of Belgian health journalists, which gives us an indication of their 
importance as a potential news source. We repeated this exercise for the subsample of 303 health-related "followings" (figure 2).

\section{$\underline{\text { Results }}$}

The number of "followings" differs significantly between the six journalists. De Cleene (EOS magazine - 110), Baekelandt (Plus Magazine - 102) and Maes (Goed Gevoel - 100) monitor approximately 100 potential sources. Finoulst (Bodytalk - 292) and Eckert (De Standaard - 228) follow more than 200 actors, but the most active health journalist in monitoring Twitter is Vandekerckhove (De Morgen). She follows 622 potential sources. One could interpret this finding in that the first three journalists use Twitter less intensively as a monitoring tool, but another possible interpretation is that they want to focus their attention on a small amount of important potential sources. Also, it can be a reflection of their evolving career paths. We will come back to this point later.

\section{$\underline{R Q 1: \text { Which actors are most followed by Belgian health journalists? }}$}

With a total of 502, or 43.9 per cent of all 1146 unique "followings", media actors outnumber all other actors. Academic and medical experts (22.0 per cent) follow at the second rank. Politicians count for 9.1 per cent of the monitored actors. Twitter is not intentionally used by the journalist to reach out to bottom-up actors; civil society organizations (6.2 per cent) and ordinary citizens (5.8 per cent) occupy respectively the fourth and seventh place. Also government actors (6.0 per cent), (pharmaceutical) industry (6.2 per cent), and health insurance companies (1.0 per cent) are less monitored. A more broad comparison of elite ( 88.0 per cent) and non-elite (12.0 per cent) actors further reflects the imbalance between the different types of potential sources. Belgian health journalists prefer to monitor elitist above bottom-up actors on Twitter. These findings indicate that the "following" practices of health journalists on Twitter resemble their offline sourcing practices. The descriptive results also confirm that Twitter is mainly used by our 6 health journalists as a "press club" to engage with other journalists and monitor competitors (Lawrence et al., 2014; Rupar, 2015) thus reflecting a process of intermedia agenda setting (Len-Rios et al., 2009). When it comes to the six health journalists, there is a reciprocal relationship between Finoulst who is followed by De Cleene, Vandekerckhove and Eckert and who follows them all back. This suggests (1) that Marleen Finoulst is an opinion leader for the other health journalists, takes a central position in the "following" network (cf. infra) and follows them back out of politeness or (2) that Finoulst monitors health journalists who follow her back out of politeness. In addition, Vandekerckhove also follows Eckert. The magazine journalists seem to be more isolated from the other health journalists as they don't follow and are not followed by any of the journalists in the sample. The findings concerning the monitoring of academic and medical experts are also in accordance with the idea that health information is often very complex which makes journalists turn to experts on the matter for clarification and contextualization (Len-Rios et al., 2009).

Actors who are followed by several journalists take a more central position in the overarching Twitter network of Belgian health journalists, which gives us an indication of their importance as a potential news source. On average, each actor is followed by 1.27 journalists. Most actors (926 or 80.8 per cent) are followed by only one journalist. 154 (13.4 per cent) of the "followings" are monitored by two journalists. A few are followed by three ( 47 or 4.1 per cent), 
four (16 or 1.4 per cent) and five ( 3 or 0.3 per cent) journalists. This finding is in line with the "power law" or "long tail" distribution of social network sites where very few actors take a central position while the large majority of actors are not systematically monitored by the journalists (D'heer \& Verdegem, 2014). In line with our other findings, the three actors that are followed by five of the six journalists are all health-related experts and media: the Brussels University Hospital, Domus Medica (the Flemish association of general practitioners), and Artsenkrant (a magazine targeted at medical professionals). On a group level ${ }^{1}$, government actors and health insurance companies are more central as they are followed on average by respectively 1.57 and 1.55 journalists. Experts (1.33) and media actors (1.27) follow at the third and fourth rank. Despite their numerical dominance in the "following" network, not all experts and media actors take a central position in the network, which points out that news access is also unevenly distributed between the potential sources in a single category. Civil society organizations (1.21) and politicians (1.19) take the fifth and sixth rank. The least central actors are industry (1.07) and ordinary citizens (1.09), which confirms again that journalists do not use Twitter's "following" function to reach out to these potential sources.

\section{(insert Table 1)}

Table 1 shows that a breakdown by individual journalists does not immediately uncover major shifts in the monitoring of potential sources, even though we still find some significant differences. The most important difference lies in the following of experts. While almost all journalists mainly follow media actors, Finoulst (Bodytalk magazine) and De Cleene (EOS Magazine) primarily monitor experts. Eckert (De Standaard) and Maes (Goed Gevoel) circle around the average, while Vandekerckhove (De Morgen) and Baekelandt (Plus Magazine) follow much fewer experts and instead follow more politicians and government actors. A possible explanation for this finding relates to their respective publication outlets and backgrounds. Finoulst and De Cleene work for two explicitly scientific (EOS Magazine) and even health-related (Bodytalk magazine) news outlets, while the other journalists work for more general news outlets. Moreover, Vandekerckhove has only recently chosen health news as a new specialization, while before she was covering social issues and defense. Thus her Twitter "followings" might also reflect this recent change, and include more not health-related actors and less experts. It also explains why she follows over 600 actors. We will come back to this point when we discuss the second research question.

De Cleene (EOS Magazine) deviates from the other journalists in other ways too as he monitors almost exclusively the two dominant actors, media and experts (31.8 per cent and 48.2 per cent) which indeed suggests that he uses Twitter very selectively to target a small amount of very significant potential sources. Also notable is that he follows civil society organizations much more than his colleagues do (13.6 per cent).

(insert Figure 1)

Figure 1 endorses the above findings. As explained in the methodological section, we used Gephi to visualize the networks of the studied health journalists by mapping the connections between health journalists and the monitored actors. The size of the pink nodes indicates how 
much these actors are followed by the health journalists in the overall "following" network. It shows that media and experts take a more central position in the overarching Twitter "following" network of the six Belgian health journalists. Bottom-up actors are rather small nodes in the network. Furthermore, it also shows the different ego-networks of the six journalists, as the thickness of the arrows departing from the colored journalist nodes indicates to what extent they follow the different types of actors. For example, Decleene follows more experts than Baekelandt who follows more media actors.

\section{RQ2: Which health-related actors are most followed by Belgian health journalists?}

26,4 percent or 303 of the 1146 "followings" are related to the health field. Interestingly, the top three "followings" specifically related to the health field looks quite different compared to the ranking of all "followings". Experts are by far the most followed actors (46.9 per cent) which is in line with traditional sourcing practices for health news (Len-Rios et al., 2009). Media actors are still on a second place but on a big distance from experts (15.8 per cent). Government institutions are on a third place (11.9 per cent) and are more important than politicians (5.0 per cent), pharmaceutical enterprises (5.0 per cent), health insurance companies (3.6 per cent), civil society organizations (8.3 per cent) and ordinary citizens (3.6 per cent). These figures confirm again the imbalance between monitored elite and non-elite actors. Health-related bottom-up actors are much less followed than health-related elites (11.9 per cent versus 88.1 per cent). Figure 2 visualizes how prominent the different types of actors are in the health-related "following" network (size of the pink nodes).

If we look at the position of the actors in the "following" network, we find that health-related actors are more central than actors who are not related to the health field. Each health-related actor is followed on average by 1.48 journalists compared to actors who are not related to the health sector who are monitored on average by 1.19 journalists $(\mathrm{p}=0.000)$. We find again that most of the 303 health-related actors (207 or 68.3 per cent) are monitored by only one journalist. 63 (20.8 per cent) are followed by two journalists, and very few possible sources are monitored by three ( 19 or 6.3 per cent), four ( 11 or 3.6 per cent) and five ( 3 or 1.0 per cent) journalists. What is remarkable here is that the two most central health-related actors are politicians (1.93) and government actors (1.75). Despite the fact that in absolute numbers they are not dominant, they are nonetheless central nodes in the health-related "following" network of Belgian health journalists as they are monitored by more journalists compared to the other types of potential sources. The scores of the other health-related actors are comparable to those of the actors in the overall "following" network. Health insurance companies (1.55), media (1.54) and experts (1.45) complete the top 5. Ordinary citizens (1.36), civil society organizations (1.20) and industry (1.00) bring up the rear. ${ }^{2}$

\section{(insert Table 2)}

If we look at the figures for each individual journalist we notice some striking results (see table 2). Health-related actors are far less dominant in the Twitter network than we expected. Vandekerckhove (De Morgen), who follows in total 622 possible sources only monitors 93 (15.0 per cent) health actors. De Cleene (EOS magazine) follows 30 health actors $(27.3$ per 
cent), Eckert (De Standaard) 82 (36.0 per cent) and Finoulst (Body magazine) 140 (47.9 per cent). Health actors are relatively more important in the Twitter network of Baekelandt (Plus magazine) and Maes (Goed Gevoel magazine). Respectively 51 (50.0 per cent) and 53 (53.0 per cent) actors are health-related. These findings might indicate that some of the journalists use Twitter more intensively for health-related news gathering while other journalists use it more to monitor actors in their personal (opposed to professional) field of interest. Alternatively, these findings might also point out individual differences. For example, Vandekerckhove's large amount of total "followings" (over 600) and low level of health-related "followings" might reflect her evolving career as she has been covering different issues with health news as the most recent one. Monitored actors from previous specializations are then still in the list and are being complemented with health-related actors. Moreover, the journalists who monitor relatively more health-related actors (Finoulst, Maes and Baekelandt) are the more experienced journalists with a longer career in covering health-related issues (Vandekerckhove, Eckert and De Cleene are younger). Alternatively, it is also important to look at the absolute numbers: Finoulst (140), Vandekerckhove (93) and Eckert (82) follow most health-related actors. For Finoulst, we assume that she also taps into her large professional network that she built up in her previous career as a physician. For their part, Vandekerckhove and Eckert work for newspapers and are confronted with daily deadlines. It would be interesting to further examine whether newspaper journalists make more use of Twitter as an information channel compared to weekly or monthly magazine journalists because they face shorter and more deadlines and thus Twitter can be a useful tool to keep abreast of topical matters.

(insert Figure 2)

Most journalists follow indeed mainly health-related experts. Only Baekelandt (Plus Magazine) monitors more media actors. Table 2 confirms that government institutions are an important third potential source. However, De Cleene (EOS Magazine) follows this type of actors much less than his colleagues while civil society organizations are more important actors for him. Also Finoulst (Body magazine) follows more civil society organizations compared to her peers. Nevertheless, the number of civil society actors remains relatively limited. Figure 2 visualizes the ego-networks of the different journalists (thickness of the arrows).

\section{Discussion}

This paper set out to explore the Twitter "following" practices of six Belgian health journalists. The goal of the study was to examine what types of potential sources are most followed by the journalists. Our analysis confirms that top-down actors are overrepresented in the "following" networks and that Twitter's "following" function is not used to reach out to bottom-up actors. We also found important differences between the overall "following" network and the "following" network in terms of health-related actors. In the overall network, we found that the journalists mainly use Twitter as a "press club" (Rupar, 2015) and predominantly monitor media actors, which relates to inter-media agenda setting, as news organizations and journalists monitor other news organizations and journalists to keep track of each other's behavior in a highly competitive news landscape. If we zoom in specifically on the "following" network of the health-related actors, we found that media are still important, but experts are the most 
followed group of potential sources. This is in line with previous studies that pointed out that experts are preferred sources for reasons of contextualization and interpretation of technical and compound health information (Len-Rios et al., 2009). Bottom-up sources and especially ordinary citizens are underrepresented in the "following" networks.

In addition, the findings show that certain actors are more central in the "following" networks of Belgian health journalists. On the one hand, the analysis confirms the "power law" or "long tail" distribution of social network sites where very few actors take a central position while the large majority of actors remain largely invisible (D'heer \& Verdegem, 2014). A few actors are monitored by two or more journalists, but four fifths of all "followings" and two thirds of all health-related "followings" are monitored by only one journalist. Many other potential sources are not monitored at all. On the other hand, the fact that the six health journalists mainly follow different actors can also be viewed as a positive finding in that this might result in a monitoring of diverse viewpoints and pieces of information. The fact that the six health journalists monitor different potential sources can also give them a competitive edge to come up with unique information. Relatedly, the fact that most journalists monitor a lot of actors (ranging between 100 and 622) points out that Twitter is the perfect channel for efficient news monitoring. Information is pushed to journalists in a very concise (140 characters) manner, which allows them to follow many potential sources with a limited investment of time and energy.

With this study we contributed to the theoretical, practical and methodological development of journalism and journalism studies. We demonstrated how digital methods and network analysis can be helpful for the study of journalism in a digital media ecology. Also, we filled a gap in terms of how health journalists can use Twitter's "following" function for news gathering and what this implies for the potential of "inclusive journalism". Yet the findings of our study cannot be generalized to the broader population of journalists due to the limited scope of our sample (six journalists). More research including more journalists in different specialty areas and in different countries is necessary. Another limitation of our study lies in our operationalization of potential sources as the "followings" of journalists. There are studies indicating that journalists follow actors because they expect them to share newsworthy information (Hill, 2010), but it is clear that actors who are monitored by journalists on Twitter are not automatically used as sources in the news gathering process (e.g. friends or family who are followed for personal, not professional, reasons). In addition, due to Twitter's nonreciprocal and information sharing characteristics, journalists can also include sources in the news process that they do not follow themselves but whose tweets they pick up in for example a search, retweet or @ mention process. As such, it is evident that the journalists follow central information nodes in the health sector who provide regular updates on health issues (experts, government) and it is not a surprise that they do not systematically follow a lot of ordinary citizens. Yet our assumption is that other Twitter functions may be more useful to source ordinary citizens. For example, when a news piece about the reimbursement of a medicine for a specific disease requires a human interest angle in terms of a patient testimony, the Twitter search functions (hashtag, keyword search, private message, ...) can be very useful to get in touch with potential sources for this specific story.

Notwithstanding this limitation, our finding that the overall "following" network differs significantly from the health-related "following" network underwrites our assumption that journalists monitor certain actors for a specific purpose, namely to gather information and story 
ideas for specific topics or issues. Further research (e.g. in-depth interviews, content analysis) could further explore to what extent Twitter "followings" are also used by journalists as sources in the news and to what extent other Twitter features are used in the newsgathering and sourcing process. In addition, our data were collected on 4 July 2015 and are thus a snapshot in time of the "following" networks. It would be interesting to conduct follow-up studies to evaluate how these networks develop and change over time.

\section{Notes}

${ }^{1}$ Government actors are followed by significantly more journalists than media $(\mathrm{p}=0.05)$, industry ( $\mathrm{p}=0.02)$, ordinary citizens $(\mathrm{p}=0.06)$, and politicians $(\mathrm{p}=0.037)$. The other differences are not significant.

${ }^{2}$ According to the ANOVA test, there is a modest significant correlation between type of actor and number of "following" journalists $(\mathrm{p}=0.021)$. Yet the post-hoc Scheffe test did not find significant differences between groups.

\section{Bibliography}

Berkowitz, D. (1990). Refining the Gatekeeping Metaphor for Local Television News. Journal of Broadcasting \& Electronic Media, 34(1): 55-68.

Broersma, M. \& Graham, T. (2012). Social Media as Beat: Tweets as News Source during the 2010 British and Dutch Elections. Journalism Practice, 6(3): 403-419.Canter, L. (2015). Personalised Tweeting: The Emerging Practices of Journalists on Twitter. Digital Journalism, 3(6): 888-907.

Carrera Alvarez, P.; Sainz de Baranda Andujar, C.; Herrero Curiel, E. and Limon Serrano, N. (2012). Journalism and Social Media: How Spanish Journalists are Using Twitter. Estudios Sobre El Mensaje Periodistico, 18(1): 31-53.

Castells, M. (2008). The New Public Sphere: Global Civil Society, Communication Networks, and Global Governance. Annals of the American Academy of Political and Social Science, 616: 78-93.

Castells, M. (2011). A Network Theory of Power. International Journal of Communication, 5: 773-787.

Cottle, S. (2000). Rethinking News Access. Journalism Studies, 1(3): 427-448.

D'heer, E. \& Verdegem, P. (2014). Conversations about the Elections on Twitter: Towards a Structural Understanding of Twitter's Relation with the Political and the Media Field. European Journal of Communication, 29(6): 720-734.

Davies, N. (2008). Flat Earth News: An Award-Winning Reporter Exposes Falsehood, Distortion and Propaganda in the Global Media. London: Vintage.

Davis, A. (2000). Public Relations, News Production and Changing Patterns of Source Access in the British National Media. Media, Culture and Society, 22(1): 39-59.

Engesser, S. \& Edda Humprecht (2015). Frequency or Skillfulness. Journalism Studies, 16(4): 513-529.

Farhi, P. (2009). The Twitter Explosion. American Journalism Review, 31(3): 26-31. 
Gandy, O. (1982). Beyond Agenda Setting: Information Subsidies and Public Policy. Norwood: Ablex.

Gans, H.J. (1979). Deciding What's News. London: Constable.

Gans, H.J. (2011). Multiperspectival News Revisited: Journalism and Representative Democracy. Journalism, 12(1): 3-13.

Greer, C.F. and Ferguson, D.A. (2011). Using Twitter for Promotion and Branding. Journal of Broadcasting \& Electronic Media, 55(2): 198-214.

Habermas, J. (1974). The Public Sphere: An Encyclopedia Article (1964). New German Critique, 3 (Autumn): 49-55.

Habermas, J. (1992). Further Reflections on the Public Sphere. In: C. Calhoun (Ed), Habermas and the Public Sphere (pp. 421-461). Cambridge: MIT Press.

Hall, S.; Critcher, C.; Jefferson, T.; Clarke, J. and Roberts, B. [1978] (1999). Policing the Crisis. In: H. Tumber (Ed), News: A Reader (pp. 249-256). Oxford: Oxford University Press.

Hanusch, F. \& Bruns, A. (2016). Journalistic Branding on Twitter. Digital Journalism, DOI: 10.1080/21670811.2016.1152161.

Heinrich, A. (2011). Network Journalism: Journalistic Practice in Interactive Spheres. New York: Routledge.

Heinrich, A. (2012). Foreign Reporting in the Sphere of Network Journalism. Journalism Practice, 6(5-6): 766-775.

Hermida, A. (2010). Twittering the News. Journalism Practice, 4(3): 297-308.

Herrera, S. and Requejo, J.L. (2012). 10 Good Practices for News Organizations Using Twitter. Journal of Applied Journalism and Media Studies, 1(1): 79-95.

Hill, D. (2010). Twitter: Journalism Chases the Greased Pig [unpublished master's thesis]. Denton: University of North Texas.

Hinnant, A.; Len-Ríos, M.E. and Jee Oh, H. (2012). Are Health Journalists' Practices Tied to Their Perceptions of Audience. Health Communication, 27: 234-243.

Holton, A. (2013). A Journalistic Chasm? Normative Perceptions and Participatory and Gatekeeping Roles of Organizational and Entrepreneurial Health Journalists. Austin, Texas: The University of Texas.

Kaplan, A.M. \& Haenlein, M. (2010). Users of the World, Unite! The Challenges and Opportunities of Social Media. Business Horizons, 53: 59-68.

Lariscy, R.W.; Avery, E.J.; Sweetser, K.D. and Howes, P. (2009). An Examination of the Role of Online Social Media in Journalists' Source Mix. Public Relations Review, 35(3): 314316.

Lawrence, R.G.; Molyneux, L.; Coddington, M. \& Holton, A. (2014). Tweeting Conventions. Journalism Studies, 15(6): 789-806.

Len-Rios, M.E.; Hinnant, A.; Park, S.A.; Cameron, G.T.; Frisby, C.M. and Lee, Y. (2009). Health News Agenda Building. Journalism \& Mass Communication Quarterly, 86(2): 315-331.

Lewis, J.; Williams, A. and Franklin, B. (2008). A Compromised Fourth Estate? UK News Journalism, Public Relations and News Sources. Journalism Studies, 9(1): 1-20.

Lotan, G.; Graeff, E.; Ananny, M.; Gaffney, D.; Pearce, I. and Boyd, D. (2011). The Revolutions Were Tweeted. International Journal of Communication, 5: 1375-1405. 
McNair, B. (2009). Journalism and Democracy. In: K. Wahl-Jorgensen \& T. Hanitzsch (Eds), The Handbook of Journalism Studies (pp. 237-249). New York: Routledge.

Molyneux, L and Holton, A. (2015). Branding (Health) Journalism. Digital Journalism, 3(2): 225-242.

Neuberger, C.; vom Hofe, H.J. and Nuernbergk, C. (2014). "The Use of Twitter by Professional Journalists.” In: K. Weller, A. Bruns, J. Burgess, M. Mahrt and C. Puschmann (eds.) Twitter and Society (pp. 345-357). London: Sage.

Noguera Vivo, J.M. (2013). How Open Are Journalists on Twitter? Communication \& Society/Comunicación y Sociedad, 26(1): 93-114.

Parmelee, J.H. (2014). The Agenda-Building Function of Political Tweets. New Media \& Society, 16(3): 434-450.

Paulussen, S. and Harder, R.A. (2014). Social Media References in Newspapers. Journalism Practice, 8(5): 542-551.

Pew Research Center (2011). How Mainstream Media Outlets Use Twitter. Washington, DC:

George Washington University. Accessed online:

http://www.journalism.org/2011/11/14/how-mainstream-media-outlets-use-

Twitter/?beta=true\&utm_expid=53098246-2.Lly4CFSVQG2lphsg-KopIg.1

Rowe, R.; Tilbury, F. and O'Ferrall, I. (2003). 'About a Year before the Breakdown I Was Having Symptoms'. Sociology of Health \& Illness, 25(6): 680-696.

Rupar, V. (2015). Elections and Whom Journalists Talk To: Legacy Reporting and Tweeting. Paper presented at "The Future of Journalism: Risks, Threats and Opportunities", 10-11 September 2015, Cardiff University, UK.

Russell, F.M.; Hendricks, M.A.; Choi, H. and Conner Stephens, E. (2015). Who Sets the News Agenda on Twitter? Digital Journalism, 3(6): 925-943.

Shoemaker, P.J. and Reese, S.D. (1996). Mediating the Message. New York: Longman.

Sigal, L.V. [1973] (1999). Reporters and Officials (Excerpt). In: H. Tumber (Ed), News: A Reader (pp. 224-234). Oxford: Oxford University Press.

Sumner, P. et al. (2014). The Association Between Exaggeration in Health Related Science News and Academic Press Releases. British Medical Journal, 349: 1-8.

Van Trigt, A.M.; De Jong-Van Den Berg, L.T.W.; Haaijer-Ruskamp, F.M.; Willems, J. and Tromp, T.F.J. (1994). Journalists and Their Sources of Ideas and Information on Medicines. Soc. Sci. Med., 38(4): 637-643.

Williams, A. and Gajevic, S. (2013). Selling Science? Source Struggles, Public Relations, and UK Press Coverage of Animal-Human Hybrid Embryos. Journalism Studies, 14(4): 507522.

Wolfsfeld, G. (2011). Making Sense of Media \& Politics. New York: Routledge. 
Table 1. Overview of "followings" of Belgian health journalists by type of actor $(\mathrm{N}=1146)$

\begin{tabular}{|c|c|c|c|c|c|c|c|c|c|}
\hline & Media & Industry & Government & $\begin{array}{l}\text { Health Insurance } \\
\text { companies }\end{array}$ & Experts & $\begin{array}{l}\text { Political } \\
\text { actors }\end{array}$ & Citizens & $\begin{array}{l}\text { Civil society } \\
\text { organizations }\end{array}$ & Total \\
\hline De Cleene & $\begin{array}{c}35 \\
(31.8 \%)\end{array}$ & $\begin{array}{c}0 \\
(0.0 \%)\end{array}$ & $\begin{array}{c}5 \\
(4.5 \%)\end{array}$ & $\begin{array}{c}0 \\
(0.0 \%)\end{array}$ & $\begin{array}{c}53 \\
(48.2 \%)\end{array}$ & $\begin{array}{c}1 \\
(0.9 \%)\end{array}$ & $\begin{array}{c}1 \\
(0.9 \%)\end{array}$ & $\begin{array}{c}15 \\
(13.6 \%)\end{array}$ & $\mathrm{N}=110$ \\
\hline Baekelandt & $\begin{array}{c}50 \\
(49.0 \%)\end{array}$ & $\begin{array}{c}10 \\
(9.8 \%)\end{array}$ & $\begin{array}{c}14 \\
(13.7 \%)\end{array}$ & $\begin{array}{c}4 \\
(3.9 \%)\end{array}$ & $\begin{array}{c}16 \\
(15.7 \%)\end{array}$ & $\begin{array}{c}3 \\
(2.9 \%)\end{array}$ & $\begin{array}{c}1 \\
(1.0 \%)\end{array}$ & $\begin{array}{c}4 \\
(3.9 \%)\end{array}$ & $\mathrm{N}=102$ \\
\hline Finoulst & $\begin{array}{c}80 \\
(27.4 \%)\end{array}$ & $\begin{array}{c}19 \\
(6.5 \%)\end{array}$ & $\begin{array}{c}23 \\
(7.9 \%)\end{array}$ & $\begin{array}{c}5 \\
(1.7 \%)\end{array}$ & $\begin{array}{c}106 \\
(36.3 \%)\end{array}$ & $\begin{array}{c}18 \\
(6.2 \%)\end{array}$ & $\begin{array}{c}13 \\
(4.5 \%)\end{array}$ & $\begin{array}{c}28 \\
(9.6 \%)\end{array}$ & $\mathrm{N}=292$ \\
\hline Eckert & $\begin{array}{c}108 \\
(47.4 \%)\end{array}$ & $\begin{array}{c}3 \\
(1.3 \%)\end{array}$ & $\begin{array}{c}27 \\
(11.8 \%)\end{array}$ & $\begin{array}{c}0 \\
(0.0 \%)\end{array}$ & $\begin{array}{c}55 \\
(24.1 \%)\end{array}$ & $\begin{array}{c}16 \\
(7.0 \%)\end{array}$ & $\begin{array}{c}8 \\
(3.5 \%)\end{array}$ & $\begin{array}{c}11 \\
(4.8 \%)\end{array}$ & $\mathrm{N}=228$ \\
\hline Vandekerckhove & $\begin{array}{c}322 \\
(51.8 \%)\end{array}$ & $\begin{array}{c}37 \\
(5.9 \%)\end{array}$ & $\begin{array}{c}29 \\
(4.7 \%)\end{array}$ & $\begin{array}{c}5 \\
(0.8 \%)\end{array}$ & $\begin{array}{c}81 \\
(13.0 \%)\end{array}$ & $\begin{array}{c}82 \\
(13.2 \%)\end{array}$ & $\begin{array}{c}41 \\
(6.6 \%)\end{array}$ & $\begin{array}{c}25 \\
(4.0 \%)\end{array}$ & $\mathrm{N}=622$ \\
\hline Maes & $\begin{array}{c}41 \\
(41.0 \%)\end{array}$ & $\begin{array}{c}7 \\
(7.0 \%)\end{array}$ & $\begin{array}{c}10 \\
(10.0 \%)\end{array}$ & $\begin{array}{c}3 \\
(3.0 \%)\end{array}$ & $\begin{array}{c}24 \\
(24.0 \%)\end{array}$ & $\begin{array}{c}4 \\
(4.0 \%)\end{array}$ & $\begin{array}{c}8 \\
(8.0 \%)\end{array}$ & $\begin{array}{c}3 \\
(3.0 \%)\end{array}$ & $\mathrm{N}=100$ \\
\hline $\begin{array}{l}\text { ALL } \\
\text { JOURNALISTS }\end{array}$ & $\begin{array}{c}502 \\
(43.9 \%)\end{array}$ & $\begin{array}{c}71 \\
(6.2 \%)\end{array}$ & $\begin{array}{c}69 \\
(6.0 \%)\end{array}$ & $\begin{array}{c}11 \\
(1.0 \%)\end{array}$ & $\begin{array}{c}252 \\
(22.0 \%)\end{array}$ & $\begin{array}{c}104 \\
(9.1 \%)\end{array}$ & $\begin{array}{c}66 \\
(5.8 \%)\end{array}$ & $\begin{array}{c}71 \\
(6.2 \%)\end{array}$ & $\mathrm{N}=1146$ \\
\hline
\end{tabular}


Table 2. Overview of health-related "followings" of Belgian health journalists by type of actor $(\mathrm{N}=303)$

\begin{tabular}{|c|c|c|c|c|c|c|c|c|c|}
\hline & Media & Industry & Government & $\begin{array}{l}\text { Health } \\
\text { Insurance } \\
\text { companies }\end{array}$ & Experts & $\begin{array}{l}\text { Political } \\
\text { actors }\end{array}$ & Citizens & $\begin{array}{l}\text { Civil society } \\
\text { organizations }\end{array}$ & Total \\
\hline De Cleene & $5(16.7 \%)$ & $0(0.0 \%)$ & $1(3.3 \%)$ & $0(0.0 \%)$ & $18(60.0 \%)$ & $0(0.0 \%)$ & $1(3.3 \%)$ & $5(16.7 \%)$ & $N=30$ \\
\hline Baekelandt & $19(37.3 \%)$ & $3(5.9 \%)$ & $8(15.7 \%)$ & $4(7.8 \%)$ & $15(29.4 \%)$ & $0(0.0 \%)$ & $1(2.0 \%)$ & $1(2.0 \%)$ & $\mathrm{N}=51$ \\
\hline Finoulst & $18(12.9 \%)$ & $4(2.9 \%)$ & $16(11.4 \%)$ & $5(3.6 \%)$ & $71(50.7 \%)$ & $9(6.4 \%)$ & $3(2.1 \%)$ & $14(10.0 \%)$ & $\mathrm{N}=140$ \\
\hline Eckert & $12(14.6 \%)$ & $1(1.2 \%)$ & $17(20.7 \%)$ & $0(0.0 \%)$ & $40(48.8 \%)$ & $5(6.1 \%)$ & 4 (4.9\%) & $3(3.7 \%)$ & $\mathrm{N}=82$ \\
\hline $\begin{array}{l}\text { Vandekerckho } \\
\text { ve }\end{array}$ & 7 (7.5\%) & 5 (5.4\%) & $14(15.1 \%)$ & $5(5.4 \%)$ & $41(44.1 \%)$ & $11(11.8 \%)$ & 5 (5.4\%) & $5(5.4 \%)$ & $\mathrm{N}=93$ \\
\hline Maes & $13(24.5 \%)$ & $2(3.8 \%)$ & $7(13.2 \%)$ & $3(5.7 \%)$ & $21(39.6 \%)$ & $4(7.5 \%)$ & $1(1.9 \%)$ & $2(3.8 \%)$ & $\mathrm{N}=53$ \\
\hline $\begin{array}{l}\text { ALL } \\
\text { JOURNALISTS }\end{array}$ & 48 (15.8\%) & $15(5.0 \%)$ & 36 (11.9\%) & $11(3.6 \%)$ & 142 (46.9\%) & $15(5.0 \%)$ & 11 (3.6\%) & $25(8.3 \%)$ & $\mathrm{N}=303$ \\
\hline
\end{tabular}


Figure 1. "Following" network of Belgian health journalists

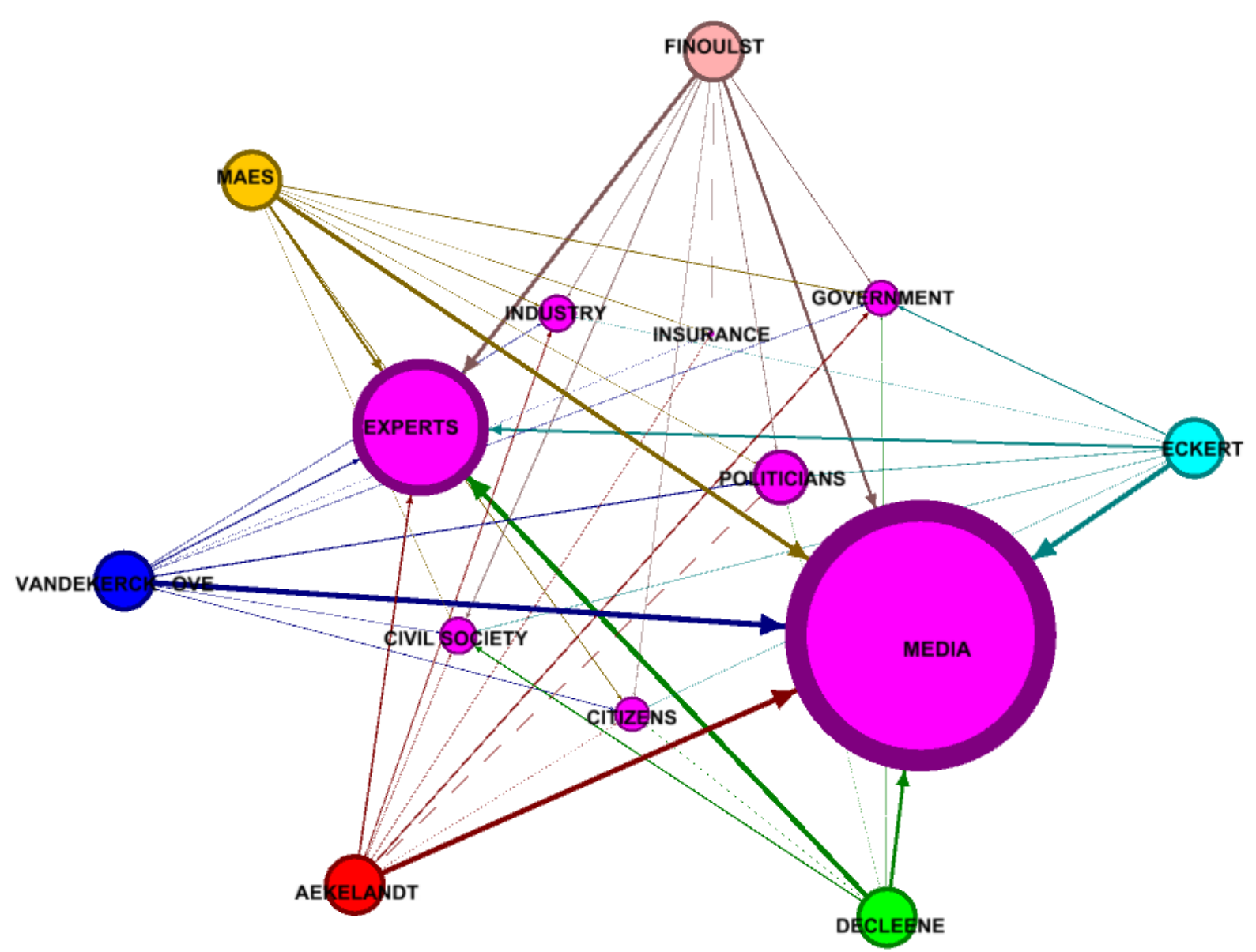


Figure 2. Health-related "following" network of Belgian health journalists

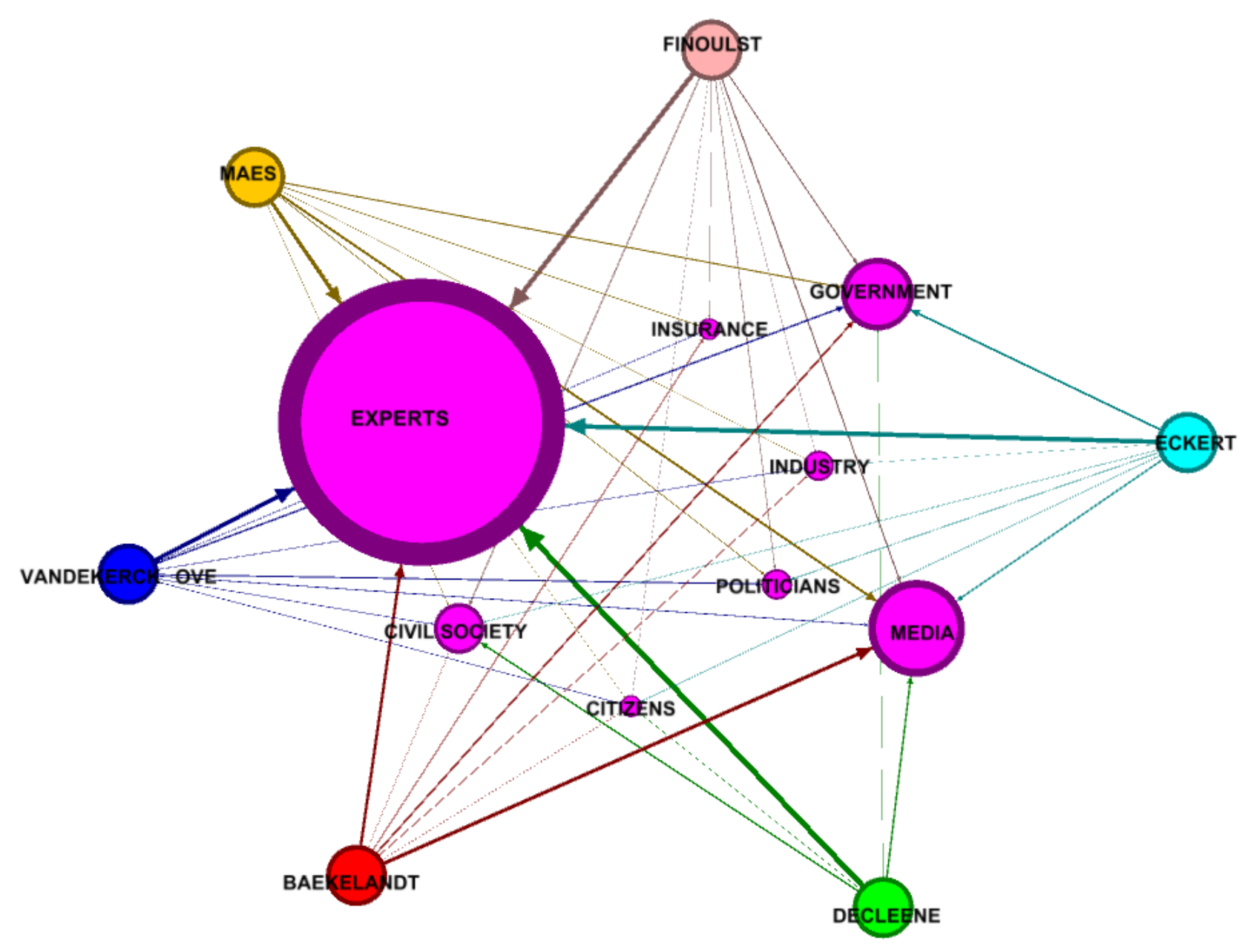

